Check for updates

Cite this: J. Mater. Chem. C, 2019, 7, 15049

Received 5th September 2019, Accepted 29th October 2019

DOI: $10.1039 / c 9 t c 04914 b$

rsc.li/materials-c

\section{Investigation on voltage loss in organic triplet photovoltaic devices based on Ir complexes $\dagger$}

\begin{abstract}
Yingzhi Jin $\star^{\mathrm{a}}$ Jie Xue, $\ddagger^{\mathrm{b}}$ Juan Qiao (DD $\star^{\mathrm{b}}$ and Fengling Zhang (D) *a
Voltage losses in singlet material-based organic photovoltaic devices (OPVs) have been intensively studied, whereas, only a few investigations on triplet material-based OPVs (T-OPVs) are reported. To investigate the voltage loss in T-OPVs, two homoleptic iridium(III) complexes based on extended $\pi$-conjugated benzo[g]phthalazine ligands, $\operatorname{Ir}\left(\mathrm{Ftbpa}_{3}\right.$ and $\operatorname{Ir}(\mathrm{FOtbpa})_{3}$, are synthesized as sole electron donors. T-OPVs are fabricated by mixing two donors with phenyl- $\mathrm{C}_{71}$-butyric acid methyl ester $\left(\mathrm{PC}_{71} \mathrm{BM}\right)$ as an electron acceptor. Insertion of oxygen-bridges as flexible inert $\delta$-spacers in Ir(FOtbpa) ${ }_{3}$ has slightly elevated both the lowest unoccupied molecular orbital and the highest occupied molecular orbital levels compared to those of $\operatorname{Ir}(\mathrm{Ftbpa})_{3}$, which results in a lower charge transfer (CT) state energy $\left(E_{\mathrm{CT}}\right)$ for $\operatorname{Ir}(\text { FOtbpa })_{3}$-based devices. However, a higher $V_{\text {oc }}(0.88 \mathrm{~V})$ is observed for $\operatorname{Ir}(\text { FOtbpa })_{3}$-based devices than those of $\operatorname{Ir}(\mathrm{Ftbpa})_{3}(0.80 \mathrm{~V})$. To understand the above result, the morphologies of the two blend films are studied, which excludes the influence of morphology. Furthermore, radiative and non-radiative recombination in two devices is quantitatively investigated, which suggests that a higher $V_{\text {oc }}$ can be attributed to reduced radiative and non-radiative recombination loss for the $\operatorname{lr}(\mathrm{FOtbpa})_{3}$-based devices.
\end{abstract}

\section{Introduction}

Solar energy is considered to be a promising renewable energy source to address the increasing worldwide energy demands. In particular, solution processed bulk-heterojunction (BHJ) organic photovoltaic devices (OPVs) have been identified as promising candidates because of their potential in low-cost, large-area, lightweight and flexible productions. To date, power conversion efficiencies (PCE) over 15\% have been achieved for single junction OPVs with the emergence of non-fullerene acceptors, ${ }^{1,2}$ which makes OPVs feasible for industrialization. The voltage losses in OPVs have been regarded as the major challenge remaining to further improve the PCE comparable with inorganic or hybrid perovskite PVs.

The open-circuit voltage $\left(V_{\text {oc }}\right)$ in OPVs is proportional to the energy of the charge transfer $(\mathrm{CT})$ state $\left(E_{\mathrm{CT}}\right)$ between the donor and acceptor. ${ }^{3}$ It has been found that the energetic difference between the highest occupied molecular orbital (HOMO) of the donor and the lowest unoccupied molecular orbital (LUMO) of the acceptor is roughly equal to $E_{\mathrm{CT}}{ }^{4-6}$ Therefore, many reports

\footnotetext{
${ }^{a}$ Department of Physics, Chemistry and Biology, Linköping University, Linköping SE-58183, Sweden. E-mail: fengling.zhang@liu.se

${ }^{b}$ Key Lab of Organic Optoelectronics and Molecular Engineering of Ministry of Education, Department of Chemistry, Tsinghua University, Beijing 100084, China. E-mail: qjuan@mail.tsinghua.edu.cn

† Electronic supplementary information (ESI) available. CCDC 1916919. For ESI and crystallographic data in CIF or other electronic format see DOI: 10.1039/c9tc04914b

\$ These authors contributed equally to this work.
}

are focused on increasing the $V_{\mathrm{oc}}$ through increasing $E_{\mathrm{CT}}$ by minimizing the energetic offset between donors and acceptors. ${ }^{7-9}$ Increasing $E_{\mathrm{CT}}$ will however lead to a small driving force (defined as the energy difference between optical gap of the neat donor or acceptor and $\left.E_{\mathrm{CT}}\right)$ for exciton dissociating to free charges. Generally, fullerene based OPVs tend to show low PCEs with small driving forces $(<0.3 \mathrm{eV})$, whereas, a reasonably high IQE (>85\%) was obtained for P3TI:PC ${ }_{71} \mathrm{BM}$ blends with a small driving force of $0.1 \mathrm{eV} .{ }^{10}$ Recently, non-fullerene based OPVs have exhibited efficient exciton dissociation despite a negligible driving force. ${ }^{11-14}$ Furthermore, the voltage loss between $E_{\mathrm{CT}} / q$ to $V_{\mathrm{oc}}$ is due to radiative and non-radiative recombination. An empirical relation of $V_{\mathrm{oc}}=\frac{E_{\mathrm{CT}}}{q}-0.6 \mathrm{~V}$, has been found for fullerene based OPVs, of which radiative recombination at donor/acceptor interfaces via the CT state causes $\sim 0.25 \mathrm{~V}$ loss and non-radiative recombination causes $\sim 0.35 \mathrm{~V}$ loss. ${ }^{3,15}$ Thus, reducing recombination losses is another important strategy to obtain a high $V_{\text {oc. }}{ }^{16}$ It was reported that decreasing the donor/ acceptor interfacial area is an effective way to reduce voltage losses. ${ }^{17}$ Therefore, high $V_{\text {oc }}$ can be achieved for organic materials with long exciton diffusion lengths, which will enable a reduced optimum interfacial area. Furthermore, reducing non-radiative recombination losses $(<0.3 \mathrm{~V})$ enabled high $V_{\mathrm{oc}}$ for materials with high photoluminescence (PL) yields, which have also been reported. ${ }^{18,19}$

At present, the photo-induced charges mainly originate from singlet exciton dissociation in high performance OPVs. 
Triplet excitons, which have longer lifetimes or diffusion lengths than singlets, may provide a favorable approach to increase the photocurrent of OPVs due to the forbidden nature of recombination from the triplet state. ${ }^{20,21}$ In addition, the long diffusion lengths are beneficial to have large domains with decreased interfaces, which will further improve $V_{\text {oc }}{ }^{17}$ In general, the excitons generated by absorbing photons in organic materials are singlet due to the selection rule in the electronic dipole transition processes. ${ }^{22}$ The triplet excitons can be obtained by flipping the spin orientation of singlet excitons through the effective intersystem crossing (ISC) or by bimolecular singlet fission. ${ }^{23,24}$ Enlarging spin-orbit coupling (SOC) by chemically or physically introducing heavy atoms into the conjugated materials has been proposed to enhance ISC rate. ${ }^{25-27}$ So far, some research studies have been done on triplet material-based OPVs (T-OPVs) ${ }^{28-31}$ and the highest PCE for small-molecule Ir complexes is 3.81\%. ${ }^{32}$ However, the voltage losses in T-OPVs were rarely investigated. ${ }^{33}$ In terms of recombination losses, the long exciton diffusion lengths and high emissive properties of triplet materials are beneficial for large $V_{\mathrm{oc}}$.

Here, we therefore investigate the voltage losses in T-OPVs via radiative and non-radiative recombination losses by employing highly sensitive external quantum efficiency and electroluminescence (EL) measurements. Two homoleptic iridium (Ir) complexes, tris(1-(2,4-bis(trifluoromethyl)phenyl)-4-(thiophen-2-yl)benzo[g]phthalazine) $\operatorname{Ir}(\mathrm{III})\left(\left(\mathrm{Ir}(\mathrm{Ftbpa})_{3}\right)\right.$ and tris(1-(2,5-bis(trifluoromethyl)phenoxy)-4-(thiophen-2-yl)benzo[g]phthalazine) $\operatorname{Ir}(\mathrm{III})$ (Ir(FOtbpa) ${ }_{3}$ ), are designed as electron donors and phenyl- $\mathrm{C}_{71}$-butyric acid methyl ester $\left(\mathrm{PC}_{71} \mathrm{BM}\right)$ is used as the electron acceptor. OPVs based on $\operatorname{Ir}(\mathrm{Ftbpa})_{3}$ and $\operatorname{Ir}(\text { FOtbpa })_{3}$ donors exhibit PCEs of $3.17 \%$ and $3.56 \%$, which are decent performances regarding the studies on T-OPVs to date, and also showed great enhancement compared to poor photovoltaic performance of the 1-chloro-4(thiophen-2-yl)benzo[g]phthalazine (Ftbpa) (0.001\%) and 1-(2,5bis(trifluoromethyl)phenoxy)-4-(thiophen-2-yl)benzo[g]phthalazine (FOtbpa) $(0.007 \%)$ ligands as donors. More importantly, a higher $V_{\text {oc }}$ is achieved for $\operatorname{Ir}(\text { FOtbpa) })_{3}$-based devices despite a lower $E_{\mathrm{CT}}$, which is attributed to the reduced radiative and non-radiative recombination loss.

\section{Experimental section}

\section{Synthesis and characterization}

All commercially available reagents and chemicals were used without further purification. All reactions involving air-sensitive reagents were carried out under an atmosphere of nitrogen.

1-Chloro-4-(thiophen-2-yl)benzo[g]phthalazine, Ftbpa and $\operatorname{Ir}(\text { Ftbpa })_{3}$ was synthesized according to the literature reports. ${ }^{34}$

Synthesis of FOtbpa. To a $50 \mathrm{~mL}$ round-bottom flask, 1-chloro4-(thiophen-2-yl)benzo[g]phthalazine (1.184 g, $4 \mathrm{mmol}$ ), 2,5-bis(trifluoromethyl)phenol $(1.20 \mathrm{~g}, 5.2 \mathrm{mmol})$, potassium carbonate (1.79 g, $13 \mathrm{mmol})$, and $N, N$-dimethylformamide $(20 \mathrm{~mL})$ were added. The mixture was heated to $110{ }^{\circ} \mathrm{C}$ under a nitrogen atmosphere for $5 \mathrm{~h}$. After cooling to room temperature, the mixture was poured into $100 \mathrm{~mL}$ water. The precipitate was then collected by filtration, and washed with water and dried in a vacuum. The crude product was purified by column chromatography on silica gel (hexane/dichloromethane $=1: 1, \mathrm{v} / \mathrm{v}$ ). Then, the crude product was recrystallized from dichloromethane/hexane to give FOtbpa as a yellow solid. Yield: $82 \%$. ${ }^{1} \mathrm{H}$ NMR $\left(600 \mathrm{MHz}, \mathrm{CDCl}_{3}\right): \delta 9.10$ (s, 1H), 9.07 (s, 1H), 8.27 (d, $J=7.8 \mathrm{~Hz}, 1 \mathrm{H}), 8.20$ (d, $J=7.8 \mathrm{~Hz}$, $1 \mathrm{H}), 7.95(\mathrm{~s}, 1 \mathrm{H}), 7.91(\mathrm{~d}, J=8.2 \mathrm{~Hz}, 1 \mathrm{H}), 7.86(\mathrm{~d}, J=3.3 \mathrm{~Hz}, 1 \mathrm{H})$, $7.82-7.75(\mathrm{~m}, 2 \mathrm{H}), 7.67(\mathrm{~d}, J=8.3 \mathrm{~Hz}, 1 \mathrm{H}), 7.64(\mathrm{~d}, J=4.9 \mathrm{~Hz}$, $1 \mathrm{H}), 7.32(\mathrm{t}, J=4.3 \mathrm{~Hz}, 1 \mathrm{H})$. HRMS $\left(\mathrm{ESI}^{+}\right) \mathrm{m} / z$ : calcd for $\mathrm{C}_{24} \mathrm{H}_{13} \mathrm{~F}_{6} \mathrm{~N}_{2} \mathrm{OS}^{+}[\mathrm{M}+\mathrm{H}]^{+}$: 491.0653, found: 491.0692 .

Synthesis of $\operatorname{Ir}(\text { FOtbpa })_{3}$. A mixture of FOtbpa (1.62 g, $\left.3.3 \mathrm{mmol}\right)$, $\mathrm{IrCl}_{3} \cdot 3 \mathrm{H}_{2} \mathrm{O}(0.35 \mathrm{~g}, 1 \mathrm{mmol})$, 2-methoxyethanol $(30 \mathrm{~mL})$ and distilled water $(10 \mathrm{~mL})$ was stirred at $110{ }^{\circ} \mathrm{C}$ for $24 \mathrm{~h}$ under nitrogen. After cooling to room temperature, $50 \mathrm{~mL}$ of distilled water was added and the precipitate was filtered off and washed with water, ethanol and hexane. The crude product was purified by column chromatography over aluminum oxide using hexane/dichloromethane $(2: 1, \mathrm{v} / \mathrm{v})$ as the eluent to give $\operatorname{Ir}(\mathrm{FOtbpa})_{3}$ as a black solid. Yield: 25\%. ${ }^{1} \mathrm{H}$ NMR (600 MHz, $\mathrm{CDCl}_{3}$ ): $\delta 9.16(\mathrm{~s}, 3 \mathrm{H}), 8.69$ (s, 3H), 8.28 $(\mathrm{d}, J=8.3 \mathrm{~Hz}, 3 \mathrm{H}), 8.17$ (d, $J=8.2 \mathrm{~Hz}, 3 \mathrm{H}), 7.82-7.78(\mathrm{~m}, 3 \mathrm{H})$, 7.78-7.73 (m, 3H), 7.34 (d, $J=4.2 \mathrm{~Hz}, 3 \mathrm{H}), 7.12(\mathrm{~s}, 3 \mathrm{H}), 6.64(\mathrm{~d}, J=$ $4.7 \mathrm{~Hz}, 3 \mathrm{H}), 6.54$ (d, $J=8.2 \mathrm{~Hz}, 3 \mathrm{H}), 5.71$ (d, $J=8.1 \mathrm{~Hz}, 3 \mathrm{H})$. HRMS (MALDI-TOF) $\mathrm{m} / \mathrm{z}$ : calcd for $\mathrm{C}_{72} \mathrm{H}_{33} \mathrm{~F}_{18} \mathrm{IrN}_{6} \mathrm{O}_{3} \mathrm{~S}_{3}{ }^{+}[\mathrm{M}]^{+}$: 1660.1118, found: 1660.2736. Elemental analysis calcd for $\mathrm{C}_{72} \mathrm{H}_{33} \mathrm{~F}_{18} \mathrm{IrN}_{6} \mathrm{O}_{3} \mathrm{~S}_{3}$ : C, 52.08; H, 2.00; N, 5.06; found: C, 52.08; H, 2.28; N, 5.19.

\section{Characterization}

${ }^{1} \mathrm{H}$ NMR spectra were measured using a JEOLAL-600 MHz spectrometer at ambient temperature. High resolution mass spectra were recorded using a Thermo-Electron Corporation Finnigan LTQ mass spectrometer (ESI-MS) and LCMS-IT/TOF (HRMS). The laser desorption ionization time-of flight mass spectrometry (LDI-TOFMS) data were obtained using a Shimadzu AXIMA Performance MALDI-TOF instrument in both positive and negative detection modes with an applied voltage of $25 \mathrm{kV}$ between the target and the aperture of the time-of-flight analyzer. Elemental analysis was performed using a flash EA 1112 spectrometer. The single crystal of $\operatorname{Ir}(\mathrm{FObpa})_{3}$ was obtained from the diffusion of a chloroform/ hexane mixture. The low temperature (104.6 K) single-crystals X-ray experiments were performed using a Rigaku RAXIS-SPIDER IP diffractometer with graphite-monochromatized MoK $\alpha$ radiation $(\lambda=0.71073 \AA)$. Data collection and reduction, cell refinement, and experiential absorption correction were performed with the Rigaku RAPID AUTO software package (Rigaku, 1998, Version 2.30). CCDC 1916919. $\dagger$ Electrochemical measurement was performed with a Potentiostat/Galvanostat Model 283 (Princeton Applied Research) electrochemical workstation, using Pt as the working electrode, platinum wire as the auxiliary electrode, and a $\mathrm{Ag}$ wire as the reference electrode standardized against ferrocene/ ferrocenium. The reduction/oxidation potentials were measured in anhydrous DMF solution containing $0.1 \mathrm{Mn} n-\mathrm{Bu}_{4} \mathrm{NPF}_{6}$ as the supporting electrolyte at a scan rate of $150 \mathrm{mV} \mathrm{s}^{-1}$.

\section{Device fabrication and characterization}

The OPVs were fabricated with the structure of ITO/poly(3,4ethylenedioxythiophene) doped with poly(styrene-sulfonate) (PEDOT:PSS)/active layer/LiF/Al. The ITO substrates were cleaned 
with detergent and TL-1 $\left(\mathrm{NH}_{3}: \mathrm{H}_{2} \mathrm{O}_{2}: \mathrm{H}_{2} \mathrm{O}=1: 1: 5\right)$ for $30 \mathrm{~min}$. PEDOT:PSS was spin-coated on the cleaned ITO substrates followed by annealing at $150{ }^{\circ} \mathrm{C}$ for $15 \mathrm{~min}$. The active layers (total $20 \mathrm{mg} \mathrm{mL}^{-1}$ ) were spin-coated from chloroform (CF) solutions on top of the PEDOT:PSS at $2000 \mathrm{rpm}$ for $40 \mathrm{~s}$ in a glovebox filled with $\mathrm{N}_{2}$. The substrates were moved into a vacuum chamber where $0.6 \mathrm{~nm} \mathrm{LiF}$ and $90 \mathrm{~nm} \mathrm{Al}$ were thermally evaporated at a pressure less than $2.0 \times 10^{-4}$ Pa with a shadow mask to define the active area to be $0.047 \mathrm{~cm}^{2}$. Hole only devices were fabricated with the structure of ITO/PEDOT:PSS/active layer $/ \mathrm{MoO}_{3} / \mathrm{Al}$. Electron only devices were fabricated with the structure of ITO/ZnO/active layer/LiF/Al. The hole or electron mobilities of the BHJ blends were measured using the spacecharge-limited current (SCLC) method according to the Murgatroyd law and using eqn (1) to fit the trap-free regions of the dark $J-V$ curves from the hole or electron only devices. ${ }^{35,36}$

$$
J=\frac{9}{8} \mu_{0} \varepsilon_{\mathrm{r}} \varepsilon_{0} \frac{\left(V-V_{\mathrm{bi}}\right)^{2}}{L^{3}} \exp \left(\frac{0.89}{k T} \gamma\left(\frac{\sqrt{V-V_{\mathrm{bi}}}}{\sqrt{L}}\right)\right)
$$

where $\varepsilon_{\mathrm{r}}$ is the relative dielectric constant of the blend (3.6), $\varepsilon_{0}$ is the vacuum permittivity, $\mu_{0}$ is the zero-field mobility, $L$ is the thickness of the active layer, $k$ is the Boltzmann constant, $T$ is the absolute temperature, and $\gamma$ is the field enhancement factor.

Current density-voltage $(J-V)$ curves are measured by using a Keithley 2400 Source Meter under an illumination of AM 1.5 simulated by a solar simulator (LSH-7320 LED Solar Simulator, Newport). External quantum efficiency (EQE) spectra were obtained using a QE-R system (Enli Technology Co. Ltd, Taiwan). UV-vis absorption spectra were recorded using a PerkinElmer Lambda 900 spectrometer. Photoluminescence (PL) and EL spectra were recorded using an Andor spectrometer (Shamrock sr-303i-B, coupled to a Newton EMCCD silicon detector cooled to $-60{ }^{\circ} \mathrm{C}$ ). For the EL measurements, a Keithley 2400 Source Meter was utilized for applying an external electric field. $\mathrm{EQE}_{\mathrm{EL}}$ was measured using a homebuilt system using a calibrated large area Si photodiode 1010B from Oriel, a Keithley 2400 Source Meter to provide voltage and record injected current, and a Keithley 485 Picoammeter to measure the emitted light intensity. Fourier-transform photocurrent spectroscopy (FTPS)-EQE was carried out using a Vertex 70 from Bruker optics, equipped with a QTH lamp, quartz beamsplitter and external detector option. A low noise current amplifier (SR570) was used to amplify the photocurrent produced upon illumination of the devices with light modulated by the FTIR. The output voltage of the current amplifier was fed back into the external detector port of the FTIR, Atomic force microscopy (AFM) was performed using a Dimension 3100 system (Digital Instruments/Veeco) with antimony (n) doped silicon cantilevers (SCM-PIT, Veeco) in tapping mode. The active layer thickness was determined using a Veeco Dektak 6M Stylus profilometer.

\section{Results and discussions}

The incorporation of the heavy-atom Ir in the organic framework could largely enhance the SOC and lead to an effective ISC rate. As a near-infrared (NIR) phosphorescent material, Ir(Ftbpa) possess UV-vis-NIR absorption with edge over $750 \mathrm{~nm}$, long phosphorescent lifetime and good solubility, which makes it a promising donor material for T-OPVs. Although a long excitedstate lifetime could be obtained in these noble-metal based dyes, the notorious bimolecular triplet-triplet annihilation between dyes, along with aggregation caused quenching (ACQ) in solid films would enhance the non-radiative rate and thus reduce the excited-state lifetime, which would shorten the exciton diffusion length. The usage of inert substituents could protect and isolate the excitons in the aggregation state and alleviate ACQ. Based on $\operatorname{Ir}(\text { Ftbpa })_{3}$, insertion of oxygen-bridges between the benzo $[g]$ phthalazine moiety and bis(trifluoromethyl)phenyl group generate bis(trifluoromethyl)phenoxy groups as flexible inert $\delta$-spacers to protect the exciton, and thus alleviate the ACQ and maintain long phosphorescent lifetimes for the aggregation states. As a result, $\operatorname{Ir}(\text { FOtbpa })_{3}$ (Fig. 1a) was designed and synthesized with the structure fully characterized by ${ }^{1} \mathrm{H}$ NMR, high-resolution mass spectrometry, elemental analysis and single-crystal X-ray diffraction measurements.

The single crystals of $\operatorname{Ir}(\mathrm{FOtbpa})_{3}$ were readily grown from a chloroform/methanol mixture. As show in Fig. 1b, the singlecrystal X-ray diffraction measurement verified that Ir(FOtbpa) possesses a facial configuration around the Ir center. The average (a)

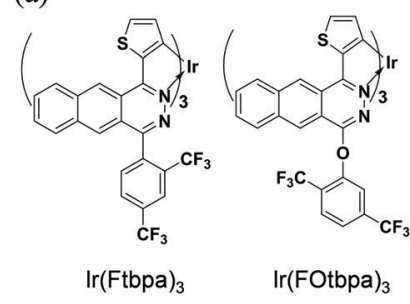

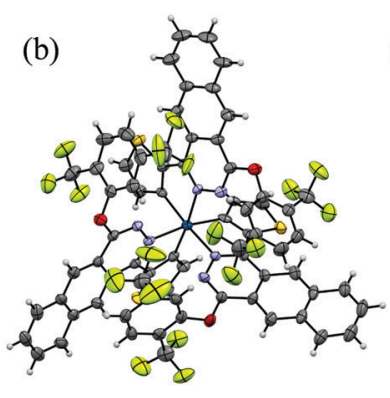

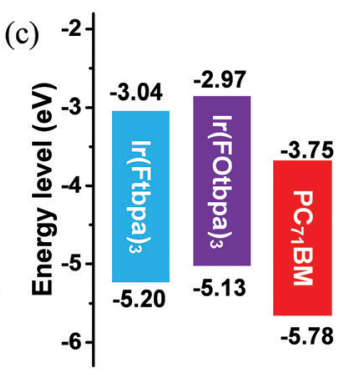

Fig. 1 (a) Chemical structures of $\operatorname{Ir}(\mathrm{Ftbpa})_{3}$ and $\operatorname{Ir}(\mathrm{FOtbpa})_{3}$ ( (b) single-crystal structure of $\operatorname{Ir}(\mathrm{FOtbpa})_{3}$ with thermal ellipsoids plotted at $50 \%$ probability level; (c) energy levels of $\operatorname{Ir}(\mathrm{Ftbpa})_{3}, \operatorname{Ir}(\mathrm{FOtbpa})_{3}$ and $\mathrm{PC}_{71} \mathrm{BM}$; (d) a schematic Jablonski diagram for the charge generation process of $\operatorname{Ir}(\mathrm{Ftbpa})_{3}: \mathrm{PC}_{71} \mathrm{BM}$ blend under photoexcitation. ISC: intersystem crossing; ground state $\left(\mathrm{S}_{0}\right)$, lowest singlet state $\left(\mathrm{S}_{1}\right)$, lowest triplet state $\left(\mathrm{T}_{1}\right)$, singlet charge transfer state $\left({ }^{1} \mathrm{CT}\right)$, triplet charge transfer state $\left({ }^{3} \mathrm{CT}\right)$, and free charges $(\mathrm{FC})$. 
$\mathrm{C}-\mathrm{O}-\mathrm{C}$ angles and the dihedral angles between the bis(trifluoromethyl)phenyl groups and the benzo[g]phthalazine cores are $117^{\circ}$ and $86^{\circ}$. Consequently, the bis(trifluoromethyl)phenoxy groups could protect the benzo[g]phthalazine moieties and Ir center at one side.

The energy levels of $\operatorname{Ir}(\text { Ftbpa })_{3}{ }^{34}$ and $\operatorname{Ir}(\text { FOtbpa })_{3}$ were estimated by cyclic voltammogram (CV) measurements (Fig. S1, ESI $\dagger$ ). The LUMO/HOMO energy levels of $\operatorname{Ir}(\text { Ftbpa })_{3}, \operatorname{Ir}(\text { FOtbpa })_{3}$, and $\mathrm{PC}_{71} \mathrm{BM}$ are calculated to be $-3.04 /-5.20,-2.97 /-5.13$, and $-3.75 /$ $-5.78 \mathrm{eV}$ (Fig. 1c), respectively. It indicates that insertion of an oxygen-bridge has no obvious effect on the electrochemical LUMO-HOMO gap while both LUMO and HOMO levels are elevated slightly.

To give readers an intuitive understanding of the charge generation process in T-OPVs, the energetic states of the Ir(Ftbpa $)_{3}$ : $\mathrm{PC}_{71} \mathrm{BM}$ blend is presented in Fig. 1d where the singlet and triplet states of $\operatorname{Ir}(\mathrm{Ftbpa})_{3}$ were calculated in a previous report, ${ }^{34}$ and the energies of the CT states is obtained from the FTPS-EQE measurement. In the charge generation process of the singlet system, the CT states are formed directly from the $S_{1}$ before being separated into free charges. While in the $\operatorname{Ir}(\mathrm{Ftbpa})_{3}: \mathrm{PC}_{71} \mathrm{BM}$ system, excitons go through a fast ISC from $S_{1}$ to $T_{1}$ (blue arrow in Fig. 1d). The energy offset between $\mathrm{T}_{1}$ and ${ }^{3} \mathrm{CT}$ may be beneficial for triplet excitons to form ${ }^{3} \mathrm{CT}$ and then dissociate into free charges (red arrow). However, this is also a possibility even in the triplet system, CT excitons might generate from $\mathrm{S}_{1}$ without going through $\mathrm{T}_{1}$ (green line).

The UV-vis absorption spectra of Ftbpa and FOtbpa ligands showed absorption bands below $450 \mathrm{~nm}$ (Fig. S2a, ESI $\dagger$ ), which could be ascribed to the $\pi-\pi^{*}$ transition. Ir complexes, $\operatorname{Ir}(\mathrm{Ftbpa})_{3}$ and $\operatorname{Ir}(\mathrm{FOtbpa})_{3}$, exhibited significantly enhanced and broadened absorption compared to Ftbpa and FOtbpa ligands shown in Fig. 2a. The bands below $450 \mathrm{~nm}$ are attributed to the ligands' absorption, while the absorption bands at 450-700 $\mathrm{nm}$ correspond to the mixed transitions of ${ }^{1}$ MLCT (metal-to-ligand charge transfer) and ${ }^{3}$ MLCT. The weak absorption band extending over $700 \mathrm{~nm}$ could be the excitation from the ground states to the lowest triplet state $\left(\mathrm{S}_{0} \rightarrow \mathrm{T}_{1}\right)$. After blending with $\mathrm{PC}_{71} \mathrm{BM}$, the blend films with a weight ratio of $1: 1.5$ showed similar absorption spectra due to the overlapped absorptions between Ir complexes and $\mathrm{PC}_{71} \mathrm{BM}$. Compared with $\operatorname{Ir}(\mathrm{Ftbpa})_{3}, \operatorname{Ir}(\mathrm{FOtbpa})_{3}$ displayed similar NIR phosphorescence with an emission peak at $767 \mathrm{~nm}$, but a lower PL quantum yield $\left(\Phi_{\mathrm{PL}}\right)$ of $10.8 \%$ and a shorter phosphorescent lifetime $\left(\tau_{\mathrm{p}}\right)$ of $489 \mathrm{~ns}$ in degassed $\mathrm{CH}_{2} \mathrm{Cl}_{2}$ (Table S1 and Fig. S2b, ESI $\dagger$ ), which are attributed to its slightly enlarged radiative transition rate constant $\left(k_{\mathrm{r}}=2.2 \times\right.$ $10^{5} \mathrm{~s}^{-1}$ ) and significantly increased non-radiative transition rate constant $\left(k_{\mathrm{nr}}=1.8 \times 10^{6} \mathrm{~s}^{-1}\right)$. The significantly increased $k_{\mathrm{nr}}$ of $\operatorname{Ir}$ (FOtbpa $)_{3}$ could be ascribed to the rotation of pendent bis(trifluoromethyl)phenoxy groups in the solution.

In neat films, the Ir(Ftbpa $)_{3}$ complex showed slightly redshifted emissions with peaks at $784 \mathrm{~nm}$ compared to that of Ir(FOtbpa $)_{3}$ with peaks at $780 \mathrm{~nm}$ (Fig. S2c, ESI $\dagger$ ), which should correspond to phosphorescence characteristics of the triplet excited states. Accordingly, the energies of $\mathrm{T}_{1}$ were estimated, by the highest energy vibronic band of the phosphorescence
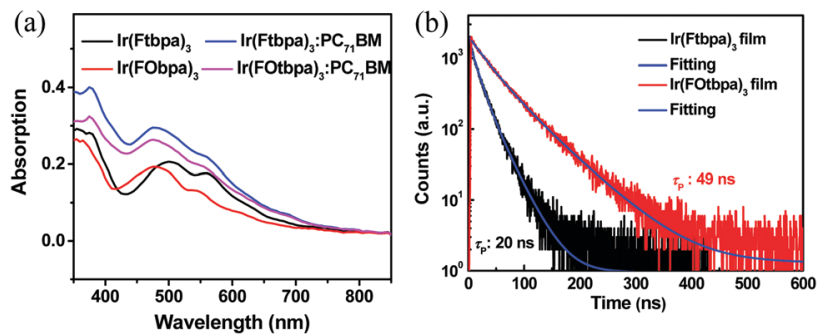

Fig. 2 (a) Absorption spectra of $\operatorname{Ir}(\mathrm{Ftbpa})_{3}, \operatorname{Ir}(\mathrm{FOtbpa})_{3}$ and corresponding blend films with $\mathrm{PC}_{71} \mathrm{BM}$ in a weight ratio of $1: 1.5$; (b) transient $\mathrm{PL}$ decay curves of $\operatorname{Ir}(\mathrm{Ftbpa})_{3}$ and $\operatorname{Ir}(\mathrm{FOtbpa})_{3}$ neat films.

spectra, to be $1.58 \mathrm{eV}$ and $1.59 \mathrm{eV}$ for $\operatorname{Ir}$ (Ftbpa $)_{3}$ and $\operatorname{Ir}$ (FOtbpa $)_{3}$, respectively. The complete elimination of the ligand fluorescence emissions indicated the strong SOC and efficient ISC rate from $\mathrm{S}_{1}$ to $\mathrm{T}_{1}$. The $\Phi_{\mathrm{PL}}$ of $\operatorname{Ir}(\mathrm{FOtbpa})_{3}$ and $\operatorname{Ir}(\mathrm{Ftbpa})_{3}$ reduced to $2.4 \%$ and $2.6 \%$ (Table $\mathrm{S} 1, \mathrm{ESI} \dagger$ ), respectively, which could be ascribed to the ACQ with enlarged $k_{\mathrm{nr}}$ caused by the interactions of triplet excitons such as triplet-triplet annihilation. Also, the $\tau_{\mathrm{p}}$ of $\operatorname{Ir}(\text { FOtbpa })_{3}$ and $\operatorname{Ir}(\text { Ftbpa })_{3}$ reduced to 49 ns and 19 ns, respectively (Fig. 2b). The $k_{\text {nr }}$ of $\operatorname{Ir}(\text { FOtbpa })_{3}$ and $\operatorname{Ir}(\text { Ftbpa })_{3}$ were calculated to be $2.0 \times 10^{7} \mathrm{~s}^{-1}$ and $5.1 \times 10^{7} \mathrm{~s}^{-1}$ in neat films, respectively, which are about 11 times and 43 times larger than their $k_{\mathrm{nr}}$ in degassed $\mathrm{CH}_{2} \mathrm{Cl}_{2}$. The values of $k_{\mathrm{r}}$ were calculated to be $4.9 \times 10^{5} \mathrm{~s}^{-1}$ and $1.4 \times 10^{6} \mathrm{~s}^{-1}$ for $\operatorname{Ir}(\text { FOtbpa })_{3}$ and $\operatorname{Ir}(\text { Ftbpa })_{3}$ neat films, respectively. Since the only difference of Ir(FOtbpa) $)_{3}$ and $\operatorname{Ir}(\mathrm{Ftbpa})_{3}$ molecules is the pendent group, the much smaller enhancement of $k_{\mathrm{nr}}$ for $\operatorname{Ir}(\mathrm{FOtbpa})_{3}$ is ascribed to the usage of the bis(trifluoromethyl)phenoxy groups as $\delta$-spacers, which hamper the interactions of triplet excitons in aggregated state and alleviate the reductions of $\Phi_{\mathrm{PL}}$ and $\tau_{\mathrm{p}}$. Thus, $\operatorname{Ir}(\mathrm{FOtbpa})_{3}$ displays longer $\tau_{\mathrm{p}}$ in the pristine film, which is beneficial for the exciton diffusion.

To study the voltage losses in T-OPVs, the Ir complexes were evaluated using $\mathrm{PC}_{71} \mathrm{BM}$ as the electron acceptor with weight ratios of $2: 1,1: 1.5$ and $1: 3$. Photovoltaic parameters of the T-OPVs based on $\operatorname{Ir}(\text { Ftbpa })_{3}$ and $\operatorname{Ir}$ (FOtbpa $)_{3}$ are summarized in Table 1. For $\operatorname{Ir}(\mathrm{Ftbpa})_{3}: \mathrm{PC}_{71} \mathrm{BM}$ devices, a PCE of $3.17 \%$ with a short-circuit current density $\left(J_{\mathrm{sc}}\right)$ of $8.70 \mathrm{~mA} \mathrm{~cm}^{-2}, V_{\mathrm{oc}}$ of $0.80 \mathrm{~V}$, and fill factor $(\mathrm{FF})$ of 0.46 is obtained at a weight ratio of $1: 1.5$. For $\operatorname{Ir}(\text { FOtbpa })_{3}: \mathrm{PC}_{71} \mathrm{BM}$ devices, the best PCE increases to $3.56 \%$ with a $V_{\text {oc }}$ of $0.88 \mathrm{~V}, J_{\mathrm{sc}}$ of $8.58 \mathrm{~mA} \mathrm{~cm}^{-2}$, and $\mathrm{FF}$ of 0.47 at the same weight ratio $(1: 1.5)$. On the other hand, the Ftbpa and FOtbpa ligands showed very poor performance with low PCEs of $0.001 \%$ and $0.007 \%$ in similar device structures (Table S2, ESI $\dagger$ ), which confirms the significant contribution of Ir to the performance of corresponding T-OPVs. The typical $J-V$ and EQE curves for Ir complex-based devices with a weight ratio of $1: 1.5$ are shown in Fig. 3a and b. The EQE curves of these Ir complex-based devices showed a spectral response from both donor and acceptor absorption regions (300 to $700 \mathrm{~nm})$. The integrated $J_{\mathrm{sc}}$ values from the EQE curves are 8.26 and $8.11 \mathrm{~mA} \mathrm{~cm}{ }^{-2}$ for $\operatorname{Ir}(\mathrm{Ftbpa})_{3}: \mathrm{PC}_{71} \mathrm{BM}$ and $\operatorname{Ir}$ (FOtbpa) ${ }_{3}: \mathrm{PC}_{71} \mathrm{BM}$ devices, respectively, which are consistent with the values from $J-V$ measurement. The $J-V$ characteristics of the hole-only and electron-only devices are shown in Fig. S3a and b (ESI $\dagger$ ). 
Table 1 Summary of photovoltaic parameters of T-OPVs based on $\operatorname{Ir}(\mathrm{Ftbpa})_{3}$ and $\operatorname{Ir}(\mathrm{FOtbpa})_{3}$ with different ratios. The average values were obtained from over 20 devices

\begin{tabular}{llllll}
\hline Donor & Ratio & $V_{\text {oc }}(\mathrm{V})$ & $J_{\text {sc }}\left(\mathrm{mA} \mathrm{cm}^{-2}\right)$ & FF & PCE $(\%)$ \\
\hline Ir(Ftbpa $)_{3}$ & $2: 1$ & $0.85(0.85 \pm 0.01)$ & $6.43(6.47 \pm 0.1)$ & $0.39(0.38 \pm 0.01)$ & $2.13(2.07 \pm 0.19)$ \\
& $1: 1.5$ & $0.80(0.80 \pm 0.01)$ & $8.70(8.72 \pm 0.19)$ & $0.46(0.43 \pm 0.02)$ & $3.17(3.01 \pm 0.19)$ \\
& $1: 3$ & $0.78(0.78 \pm 0.01)$ & $8.62(8.58 \pm 0.07)$ & $0.42(0.41 \pm 0.01)$ & \\
& & & & \\
Ir(FOtbpa $)_{3}$ & $2: 1$ & $0.93(0.93 \pm 0.01)$ & $5.07(4.67 \pm 0.23)$ & $0.32(0.31 \pm 0.01)$ & $1.51(1.34 \pm 0.09)$ \\
& $1: 1.5$ & $0.88(0.88 \pm 0.01)$ & $8.58(8.41 \pm 0.51)$ & $0.47(0.45 \pm 0.02)$ & $3.56(3.30 \pm 0.26)$ \\
& $1: 3$ & $0.85(0.85 \pm 0.02)$ & $8.11(8.14 \pm 0.44)$ & $0.46(0.41 \pm 0.03)$ & $3.15(2.80 \pm 0.23)$
\end{tabular}
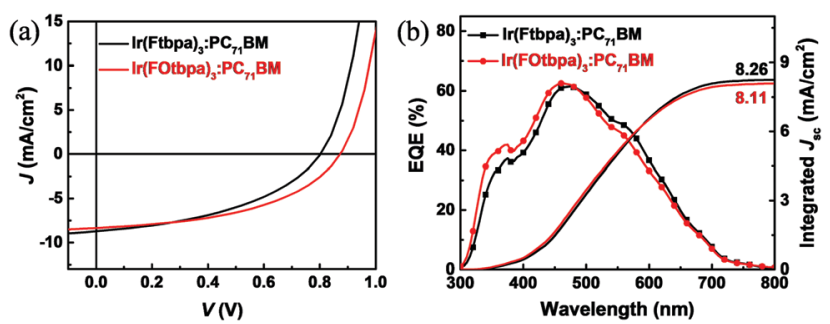

Fig. 3 (a) $J-V$ characteristics of the T-OPVs based on $\operatorname{Ir}(\text { Ftbpa })_{3}: \mathrm{PC}_{71} \mathrm{BM}$ and $\operatorname{Ir}(\mathrm{FOtbpa})_{3}: \mathrm{PC}_{71} \mathrm{BM}$ blends with a weight ratio of $1: 1.5 ;$ (b) $\mathrm{EQE}$ and integrated $J_{\text {sc }}$ of $\operatorname{Ir}(\text { Ftbpa })_{3}: \mathrm{PC}_{71} \mathrm{BM}$ and $\operatorname{Ir}(\mathrm{FOtbpa})_{3}: \mathrm{PC}_{71} \mathrm{BM}$ blends with a weight ratio of $1: 1.5$.

The hole and electron mobilities are $6.6 \times 10^{-7}$ and $1.76 \times$ $10^{-4} \mathrm{~cm}^{2} \mathrm{~V}^{-1} \mathrm{~s}^{-1}$ for $\operatorname{Ir}(\mathrm{Ftbpa})_{3}$ blends (ratio $\left.1: 1.5\right)$ and $1.5 \times$ $10^{-6}$ and $1.5 \times 10^{-4} \mathrm{~cm}^{2} \mathrm{~V}^{-1} \mathrm{~s}^{-1}$ for $\operatorname{Ir}(\text { FOtbpa })_{3}$ blends (ratio $1: 1.5$ ), as found through the SCLC measurements. The lower hole mobilities than the singlet materials resulted in unbalanced mobilities and the smaller FFs here.

Comparing the devices based on these two Ir complexes with different weight ratios, we find that the $V_{\text {oc }}$ increases with increasing content of the Ir complexes. Similar phenomena have been reported and attributed to the changes in the interfacial area of the donor/acceptor. ${ }^{17,37}$ Atomic force microscopy (AFM) was used to investigate the morphologies of the blend films with different weight ratios. As shown in the images (Fig. S4, ESI $\dagger$ ), there seem to be minor morphological differences between the different blend ratios for both $\operatorname{Ir}(\mathrm{Ftbpa})_{3}: \mathrm{PC}_{71} \mathrm{BM}$ and $\operatorname{Ir}(\mathrm{FOtbpa})_{3}: \mathrm{PC}_{71} \mathrm{BM}$ blend films. While AFM only examines the surface morphology, the phase separation of the whole active layer could be investigated by PL measurement. Steady state PL spectra of the pristine $\operatorname{Ir}(\text { Ftbpa })_{3}$ and $\operatorname{Ir}(\text { FOtbpa })_{3}$ films are compared with their corresponding blends with different weight ratios (Fig. S5, ESI $\dagger$ ). The PL intensities from $\operatorname{Ir}\left(\mathrm{Ftbpa}_{3}\right.$ and $\operatorname{Ir}(\text { FOtbpa })_{3}$ triplet excitons are strongly quenched by $\mathrm{PC}_{71} \mathrm{BM}$ in all blends, indicating efficient excitons dissociation and charge transfer between the two Ir complex donors and $\mathrm{PC}_{71} \mathrm{BM}$ acceptor with highly mixed donors and acceptors. The CT state PL from $2: 1,1: 1.5$, and $1: 3 \operatorname{Ir}(\mathrm{Ftbpa})_{3}: \mathrm{PC}_{71} \mathrm{BM}$ blend films are presented in Fig. 4a. The interfacial CT state emission is observed at $\sim 950 \mathrm{~nm}$, which is clearly red-shifted compared to $\operatorname{Ir}(\mathrm{Ftbpa})_{3}$ exciton emission at $784 \mathrm{~nm}$. Furthermore, it shows a clear trend of suppressed CT PL from the films with a higher $\mathrm{PC}_{71} \mathrm{BM}$ content. Similar results have also been found in $\operatorname{Ir}(\mathrm{FOtbpa})_{3}: \mathrm{PC}_{71} \mathrm{BM}$ blends (Fig. $4 \mathrm{~b}$ ). Since the CT PL intensities are generally very
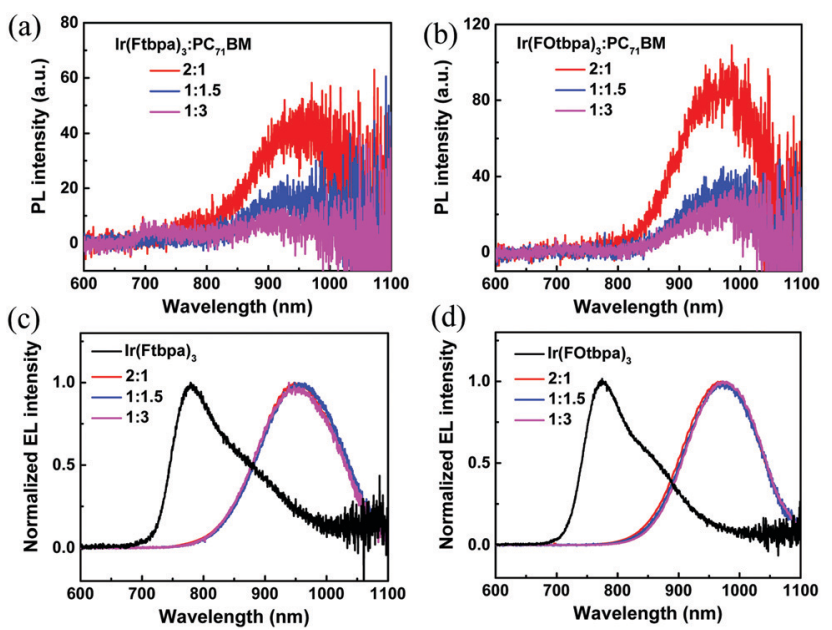

Fig. 4 Sub-band-gap PL spectra from CT transitions of (a) Ir(Ftbpa $)_{3}: \mathrm{PC}_{71} \mathrm{BM}$ and (b) Ir(FOtbpa $)_{3}: \mathrm{PC}_{71} \mathrm{BM}$ blends with different weight ratios. The films were excited by a $532 \mathrm{~nm}$ laser; (c) EL spectra for pristine $\operatorname{Ir}(\mathrm{Ftbpa})_{3}$ and $\operatorname{Ir}(\mathrm{Ftbpa})_{3}$ : $\mathrm{PC}_{71} \mathrm{BM}$ blends with different weight ratios; (d) the EL spectra of pristine $\operatorname{Ir}(\mathrm{FOtbpa})_{3}$ and $\operatorname{Ir}(\mathrm{FOtbpa})_{3}: \mathrm{PC}_{71} \mathrm{BM}$ blends with different weight ratios.

low, EL measurement is a much more sensitive method to determine the $E_{\mathrm{CT}}$. Therefore, the EL emission from devices based on pristine Ir complexes and their blends are also recorded. As shown in Fig. 4c and d, these electrically generated CT state EL emissions are consistent with the CT state PL emissions generated by photoexcitation. The $\operatorname{Ir}(\mathrm{Ftbpa})_{3}: \mathrm{PC}_{71} \mathrm{BM}$ blend films showed red-shift EL emissions at around $950 \mathrm{~nm}$ compared to $780 \mathrm{~nm}$ for the pristine $\operatorname{Ir}(\mathrm{Ftbpa})_{3}$ devices (Fig. 4c). Similar red-shift EL emissions are observed in the $\operatorname{Ir}(\text { FOtbpa })_{3}$ : $\mathrm{PC}_{71} \mathrm{BM}$ blends (Fig. 4d) at around $973 \mathrm{~nm}$. These indicate that the triplet energy of $\operatorname{Ir}(\mathrm{Ftbpa})_{3}$ and $\operatorname{Ir}(\mathrm{FOtbpa})_{3}$ are much higher than the $E_{\mathrm{CT}}$ in the blends, which confirms the effective utilization of triplet excitons in the charge generation process.

More specifically, the $E_{\mathrm{CT}}$ can be determined through fitting the FTPS-EQE spectra according to the model developed by Vandewal based on Marcus theory.

$$
\mathrm{EQE}_{\mathrm{PV}}(E)=\frac{f}{E \sqrt{4 \pi \lambda K T}} \exp \left(\frac{-\left(E_{\mathrm{CT}}+\lambda-E\right)^{2}}{4 \lambda K T}\right)
$$

where $f$ is proportional to the absorption strength of the CT state, $K$ is the Boltzmann's constant, $T$ is the absolute temperature and $\lambda$ is the reorganization energy. FTPS-EQE spectra and corresponding fits by eqn (2) of these two Ir complex blends are 

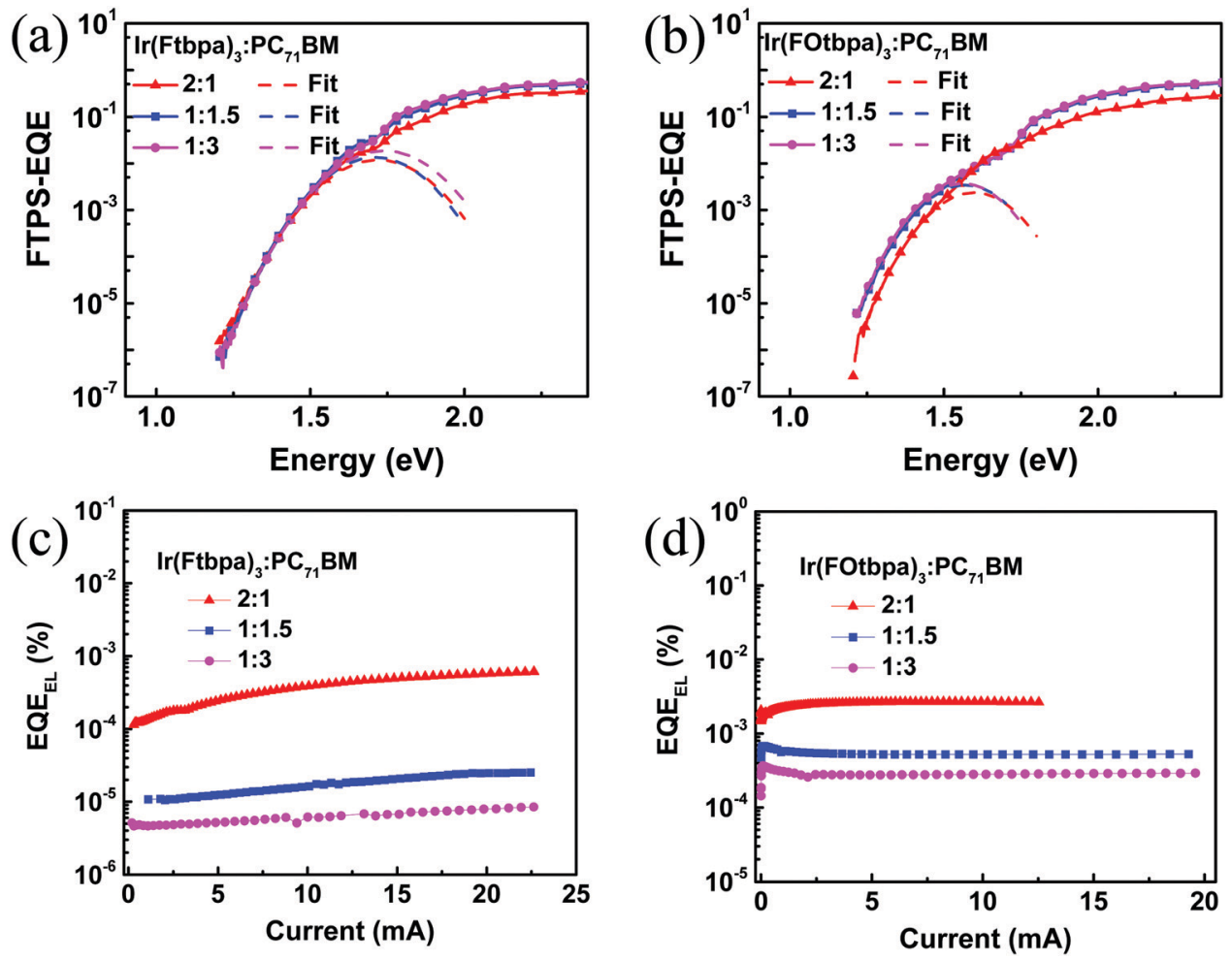

Fig. 5 FTPS-EQE spectra of (a) $\operatorname{Ir}(F t b p a)_{3}: P C_{71} B M$ and (b) $\operatorname{Ir}(F O t b p a)_{3}: P C_{71} B M$. The dash curves are fits of the FTPS-EQE spectra using eqn (2); (c) EQE $E_{E L}$ of the $\operatorname{Ir}(\mathrm{Ftbpa})_{3}: \mathrm{PC}_{71} \mathrm{BM}$ and $(\mathrm{d}) \operatorname{Ir}(\mathrm{FOtbpa})_{3}: \mathrm{PC}_{71} \mathrm{BM}$.

shown in Fig. 5a and b, respectively. For the $\operatorname{Ir}(\text { Ftbpa })_{3}$-based devices, $E_{\mathrm{CT}}$ values of $1.46 \mathrm{eV}, 1.47 \mathrm{eV}$, and $1.48 \mathrm{eV}$ are obtained for the $2: 1,1: 1.5$, and $1: 3$ blends. For the $\operatorname{Ir}(\text { FOtbpa) })_{3}$-based devices, $E_{\mathrm{CT}}$ values of $1.41 \mathrm{eV}, 1.38 \mathrm{eV}$, and $1.38 \mathrm{eV}$ are obtained for the $2: 1,1: 1.5$, and $1: 3$ blends.

As shown in Table 1, the $V_{\text {oc }}$ of the OPVs based on $\operatorname{Ir}(\mathrm{Ftbpa})_{3}$ are in the range of $0.85-0.78 \mathrm{~V}$ and the $V_{\mathrm{oc}}$ of the OPVs based on $\operatorname{Ir}(\text { FOtbpa })_{3}$ are in the range of $0.93-0.85 \mathrm{~V}$. The contradiction between $E_{\mathrm{CT}}$ and $V_{\mathrm{oc}}$ for different blend ratios motivates us to further understand the voltage losses. Considering the detailed balance theory, the $V_{\text {oc }}$ of OPVs is then determined by eqn (3), where radiative ( $\left.q \Delta V_{\text {rad }}\right)$ and non-radiative ( $\left.q \Delta V_{\text {non-rad }}\right)$ recombination losses can be experimentally determined by the fitting parameters and measured $\mathrm{EQE}_{\mathrm{EL}}$.

$$
\begin{aligned}
V_{\mathrm{oc}} & =\frac{E_{\mathrm{CT}}}{q}-q \Delta V_{\mathrm{rad}}-q \Delta V_{\mathrm{non}-\mathrm{rad}} \\
& =\frac{E_{\mathrm{CT}}}{q}+K T \ln \left(\frac{J_{\mathrm{SC}} h^{3} c^{2}}{f q 2 \pi\left(E_{\mathrm{CT}}-\lambda\right)}\right)+k T \operatorname{In}\left(\mathrm{EQE}_{\mathrm{EL}}\right)
\end{aligned}
$$

where $\mathrm{EQE}_{\mathrm{EL}}$ is the external quantum efficiency of the EL of the device.

The $q \Delta V_{\text {rad }}$ and $q \Delta V_{\text {non-rad }}$ for blends with different ratios were calculated (Table 2). The $q \Delta V_{\text {rad }}$ for both $\operatorname{Ir}(\text { Ftbpa })_{3}$ and $\operatorname{Ir}(\text { FOtbpa })_{3}$-based devices is independent with blend ratios. From the $\mathrm{EQE}_{\mathrm{EL}}$ measurements (Fig. 5c, d and Table 2), the $\mathrm{EQE}_{\mathrm{EL}}$ of the $\operatorname{Ir}(\mathrm{Ftbpa})_{3}$ and $\operatorname{Ir}(\mathrm{FOtbpa})_{3}$-based devices decreased with increasing content of $\mathrm{PC}_{71} \mathrm{BM}$. These lead to low $q \Delta V_{\text {non-rad }}$ for both $\operatorname{Ir}(\mathrm{Ftbpa})_{3}$ and $\operatorname{Ir}(\mathrm{FOtbpa})_{3}$-based devices resulting in a higher $V_{\mathrm{oc}}$ with a low $\mathrm{PC}_{71} \mathrm{BM}$ content.

For the best device performances based on $\operatorname{Ir}(\mathrm{Ftbpa})_{3}$ and Ir(FOtbpa $)_{3}$ blends $(1: 1.5)$, as shown in Table 1 , the difference in the PCEs is mainly due to the difference in $V_{\mathrm{oc}}$. When we compare the energy levels of these two donors, the HOMO level of $\operatorname{Ir}(\text { Ftbpa })_{3}$ is lower than that of $\operatorname{Ir}$ (FOtbpa $)_{3}$ (Fig. 1b), which indicates that the $\operatorname{Ir}(\mathrm{Ftbpa})_{3}$ blend may have a higher $V_{\mathrm{oc}}$. However, the $V_{\text {oc }}$ of $\operatorname{Ir}(\mathrm{Ftbpa})_{3}$-based devices is $0.08 \mathrm{~V}$ lower than that of the $\operatorname{Ir}(\text { FOtbpa })_{3}$-based devices. $\operatorname{The} \operatorname{Ir}(\text { Ftbpa })_{3}$-based devices have a higher $E_{\mathrm{CT}}$ of $1.47 \mathrm{eV}$ compared with the value of $1.38 \mathrm{eV}$ for the $\operatorname{Ir}(\mathrm{FOtbpa})_{3}$-based devices, which is consistent

Table 2 Summary of fitting parameters and calculated $q \Delta V_{\text {rad }}$ and $q \Delta V_{\text {non-rad }}$ values for T-OPVs

\begin{tabular}{lllllllll}
\hline Donor & Ratio & $q V_{\text {oc }}(\mathrm{eV})$ & $f_{1}\left(\mathrm{eV}^{2}\right)$ & $E_{\mathrm{CT}}(\mathrm{eV})$ & $\lambda(\mathrm{eV})$ & $q \Delta V_{\text {rad }}(\mathrm{eV})$ & $\mathrm{EQE}_{\mathrm{EL}}(\%)$ & $q \Delta V_{\text {non-rad }}(\mathrm{eV})$ \\
\hline Ir(Ftbpa $)_{3}$ & $2: 1$ & 0.85 & $6 \times 10^{-3}$ & 1.46 & 0.27 & 0.25 & $1 \times 10^{-4}$ \\
& $1: 1.5$ & 0.80 & $6 \times 10^{-3}$ & 1.47 & 0.25 & 0.25 & 0.36 \\
& $1: 3$ & 0.78 & $9 \times 10^{-3}$ & 1.48 & 0.27 & 0.26 & $5 \times 10^{-5}$ \\
Ir(FOtbpa $)_{3}$ & $2: 1$ & 0.93 & $9 \times 10^{-4}$ & 1.41 & 0.19 & 0.21 & 0.42 \\
& $1: 1.5$ & 0.88 & $6 \times 10^{-4}$ & 1.38 & 0.12 & 0.19 & $2 \times 10^{-3}$ \\
& $1: 3$ & 0.85 & $1 \times 10^{-3}$ & 1.38 & 0.18 & 0.20 & 0.27 \\
& & & & & & & & $3 \times 10^{-4}$ \\
\end{tabular}


with the HOMO level difference. The $q \Delta V_{\text {rad }}$ for $\operatorname{Ir}(\mathrm{Ftbpa})_{3}$-based devices is $0.25 \mathrm{eV}$, which is higher than the value of $0.19 \mathrm{eV}$ for the $\operatorname{Ir}(\mathrm{FOtbpa})_{3}$-based devices. The $\mathrm{EQE}_{\mathrm{EL}}$ of the device based on $\operatorname{Ir}(\text { FOtbpa })_{3}$ is more than one order of magnitude higher than that of the $\operatorname{Ir}(\mathrm{Ftbpa})_{3}$. This leads to a calculated $q \Delta V_{\text {non-rad }}$ of $0.31 \mathrm{eV}$ for the $\operatorname{Ir}(\text { FOtbpa })_{3}$-based devices, about $0.11 \mathrm{eV}$ lower than that of the $\operatorname{Ir}(\text { Ftbpa })_{3}$-based devices. Both radiative and non-radiative recombinations for the $\operatorname{Ir}(\text { FOtbpa) })_{3}$-based devices are lower than those of the $\operatorname{Ir}(\mathrm{Ftbpa})_{3}$-based devices, which results in a higher $V_{\text {oc }}$ for the $\operatorname{Ir}$ (FOtbpa) $)_{3}$-based devices. The calculated data fit well with $V_{\text {oc }}$ in these two blends.

Contradictory to the energy gap law (the non-radiative decay rate is exponentially increasing with decreasing energy difference between the excited and ground states), the $\operatorname{Ir}(\text { FOtbpa) })_{3}$-based device has a lower $E_{\mathrm{CT}}$, but a higher $\mathrm{EQE}_{\mathrm{EL}}$. Considering the photophysical properties of the two Ir complexes, the larger $k_{\mathrm{r}}$ $\left(1.4 \times 10^{6} \mathrm{~s}^{-1}\right)$ of $\operatorname{Ir}(\text { Ftbpa })_{3}$ than that of $\operatorname{Ir}(\text { FOtbpa })_{3}\left(k_{\mathrm{r}}=4.9 \times\right.$ $\left.10^{5} \mathrm{~s}^{-1}\right)$ in solid state may correlate with the larger radiative recombination loss in $\operatorname{Ir}(\mathrm{Ftbpa})_{3}$-based devices. The longer exciton lifetime $(\tau=49 \mathrm{~ns})$ and much smaller $k_{\mathrm{nr}}(2.0 \times$ $\left.10^{7} \mathrm{~s}^{-1}\right)$ compared with those of $\operatorname{Ir}(\text { Ftbpa })_{3}(\tau=19 \mathrm{~ns}$ and $k_{\mathrm{nr}}=5.1 \times 10^{7} \mathrm{~s}^{-1}$ ) in pristine films due to the flexible inert $\delta$-spacer may decrease the non-radiative recombination loss in $\operatorname{Ir}$ (FOtbpa $)_{3}$-based devices. In addition to the above reasons, some other charge carrier loss mechanisms may coexist in the $\operatorname{Ir}(\text { Ftbpa })_{3}$-based devices.

The recombination mechanism was further studied by measuring the light intensity dependencies of $J_{\mathrm{sc}}$ and $V_{\mathrm{oc}}$ (Fig. S6, ESI $\dagger$ ). The $\operatorname{Ir}(\text { Ftbpa })_{3}$ and $\operatorname{Ir}$ (FOtbpa $)_{3}$-based devices $(1: 1.5)$ show figureof-merit $(\alpha)$ values of 0.93 and 0.92 , respectively, indicating that bimolecular recombination occurs in both systems at short circuit conditions. At open circuit conditions, a slope of $2 k_{\mathrm{BT}} / q$ for monomolecular (trap-assisted) recombination and a slope of $1 k_{\mathrm{BT}} / q$ for bimolecular recombination exist. In some cases, surface recombination would make the slope less than $1 k_{\mathrm{BT}} / q$. The $\operatorname{Ir}(\text { FOtbpa })_{3}$-based devices $(1: 1.5)$ show a slope of $1.03 k_{\mathrm{BT}} / q$, while the $\operatorname{Ir}(\mathrm{Ftbpa})_{3}$-based devices $(1: 1.5)$ show a slope less than $1 k_{\mathrm{BT}} / q\left(0.95 k_{\mathrm{BT}} / q\right)$. Thus, the $\operatorname{Ir}(\mathrm{Ftbpa})_{3}$-based devices $(1: 1.5)$ is more dominated by surface recombination than the $\operatorname{Ir}(\text { FOtbpa })_{3}$ based devices $(1: 1.5)$, which is consistent with the non-radiative recombination losses from $\mathrm{EQE}_{\mathrm{EL}}$ calculations.

\section{Conclusions}

In summary, the voltage losses in T-OPVs based on two Ir complexes and $\mathrm{PC}_{71} \mathrm{BM}$ are studied from the aspects of radiative and non-radiative recombination. Firstly, significantly increased PCE from $0.007 \%$ (devices based on ligands) to $3.56 \%$ (the $\operatorname{Ir}$ (FOtbpa $)_{3}$-based devices) was observed, which confirms the major contribution by introducing Ir. Secondly, a trend of increasing $V_{\text {oc }}$ with increasing donor contents was found in two Ir complex systems by varying the weight ratios between the donors and acceptors. Thirdly, T-OPVs based on Ir(FOtbpa) exhibited a higher $V_{\text {oc }}$ compared to $\operatorname{Ir}(\mathrm{Ftbpa})_{3}$, which could be attributed to supressed non-radiative recombination losses due to the relatively small $k_{\mathrm{nr}}$ for $\operatorname{Ir}(\mathrm{FOtbpa})_{3}$. Furthermore, the additional surface recombination in the $\operatorname{Ir}(\mathrm{Ftbpa})_{3}$-based devices also has an impact on the non-radiative recombination losses, which results in a lower $V_{\text {oc }}$.

\section{Conflicts of interest}

There are no conflicts to declare.

\section{Acknowledgements}

F. Zhang and Y. Jin acknowledge funding from the Swedish Foundation for International Cooperation in Research and Higher Education (STINT) for the Joint China-Sweden Mobility programme, the Knut and Alice Wallenberg foundation under contract 2016.0059, the Swedish Government Research Area in Materials Science on Functional Materials at Linköping University (Faculty Grant SFO-Mat-LiU No. 200900971) and the China Scholarship Council (CSC). J. Qiao would like to thank the financial support from the NSFC of China (51711530040 and 51473086). J. Xue thanks the National Postdoctoral Program for Innovative Talents (BX20180159) for the financial support.

\section{References}

1 J. Yuan, Y. Zhang, L. Zhou, G. Zhang, H.-L. Yip, T.-K. Lau, X. Lu, C. Zhu, H. Peng, P. A. Johnson, M. Leclerc, Y. Cao, J. Ulanski, Y. Li and Y. Zou, Joule, 2019, 3, 1140-1151.

2 B. Fan, D. Zhang, M. Li, W. Zhong, Z. Zeng, L. Ying, F. Huang and Y. Cao, Sci. China: Chem., 2019, 62, 746-752.

3 K. Vandewal, K. Tvingstedt, A. Gadisa, O. Inganäs and J. V. Manca, Phys. Rev. B: Condens. Matter Mater. Phys., 2010, 81, 125204.

4 M. C. Scharber, D. Mühlbacher, M. Koppe, P. Denk, C. Waldauf, A. J. Heeger and C. J. Brabec, Adv. Mater., 2006, 18, 789-794.

5 J. Widmer, M. Tietze, K. Leo and M. Riede, Adv. Funct. Mater., 2013, 23, 5814-5821.

6 K. Kawashima, Y. Tamai, H. Ohkita, I. Osaka and K. Takimiya, Nat. Commun., 2015, 6, 10085.

7 H.-Y. Chen, J. Hou, S. Zhang, Y. Liang, G. Yang, Y. Yang, L. Yu, Y. Wu and G. Li, Nat. Photonics, 2009, 3, 649.

8 S. Albrecht, S. Janietz, W. Schindler, J. Frisch, J. Kurpiers, J. Kniepert, S. Inal, P. Pingel, K. Fostiropoulos, N. Koch and D. Neher, J. Am. Chem. Soc., 2012, 134, 14932-14944.

9 W. Li, K. H. Hendriks, A. Furlan, M. M. Wienk and R. A. J. Janssen, J. Am. Chem. Soc., 2015, 137, 2231-2234.

10 K. Vandewal, Z. Ma, J. Bergqvist, Z. Tang, E. Wang, P. Henriksson, K. Tvingstedt, M. R. Andersson, F. Zhang and O. Inganäs, Adv. Funct. Mater., 2012, 22, 3480-3490.

11 J. Liu, S. Chen, D. Qian, B. Gautam, G. Yang, J. Zhao, J. Bergqvist, F. Zhang, W. Ma, H. Ade, O. Inganäs, K. Gundogdu, F. Gao and H. Yan, Nat. Energy, 2016, 1, 16089.

12 S. Li, L. Zhan, C. Sun, H. Zhu, G. Zhou, W. Yang, M. Shi, C.-Z. Li, J. Hou, Y. Li and H. Chen, J. Am. Chem. Soc., 2019, 141, 3073-3082. 
13 S. Chen, Y. Wang, L. Zhang, J. Zhao, Y. Chen, D. Zhu, H. Yao, G. Zhang, W. Ma, R. H. Friend, P. C. Y. Chow, F. Gao and H. Yan, Adv. Mater., 2018, 30, 1804215.

14 H. Fu, Y. Wang, D. Meng, Z. Ma, Y. Li, F. Gao, Z. Wang and Y. Sun, ACS Energy Lett., 2018, 3, 2729-2735.

15 Z. Tang, J. Wang, A. Melianas, Y. Wu, R. Kroon, W. Li, W. Ma, M. R. Andersson, Z. Ma, W. Cai, W. Tress and O. Inganäs, J. Mater. Chem. A, 2018, 6, 12574-12581.

16 J. Benduhn, K. Tvingstedt, F. Piersimoni, S. Ullbrich, Y. Fan, M. Tropiano, K. A. McGarry, O. Zeika, M. K. Riede, C. J. Douglas, S. Barlow, S. R. Marder, D. Neher, D. Spoltore and K. Vandewal, Nat. Energy, 2017, 2, 17053.

17 K. Vandewal, J. Widmer, T. Heumueller, C. J. Brabec, M. D. McGehee, K. Leo, M. Riede and A. Salleo, Adv. Mater., 2014, 26, 3839-3843.

18 D. Qian, Z. Zheng, H. Yao, W. Tress, T. R. Hopper, S. Chen, S. Li, J. Liu, S. Chen, J. Zhang, X.-K. Liu, B. Gao, L. Ouyang, Y. Jin, G. Pozina, I. A. Buyanova, W. M. Chen, O. Inganäs, V. Coropceanu, J.-L. Bredas, H. Yan, J. Hou, F. Zhang, A. A. Bakulin and F. Gao, Nat. Mater., 2018, 17, 703-709.

19 X. Liu, X. Du, J. Wang, C. Duan, X. Tang, T. Heumueller, G. Liu, Y. Li, Z. Wang, J. Wang, F. Liu, N. Li, C. J. Brabec, F. Huang and Y. Cao, Adv. Energy Mater., 2018, 8, 1801699.

20 P. Heremans, D. Cheyns and B. P. Rand, Acc. Chem. Res., 2009, 42, 1740-1747.

21 O. V. Mikhnenko, R. Ruiter, P. W. M. Blom and M. A. Loi, Phys. Rev. Lett., 2012, 108, 137401.

$22 \mathrm{Z} . \mathrm{Xu}, \mathrm{B} . \mathrm{Hu}$ and J. Howe, J. Appl. Phys., 2008, 103, 043909.

23 M. B. Smith and J. Michl, Chem. Rev., 2010, 110, 6891-6936.
24 D. N. Congreve, J. Lee, N. J. Thompson, E. Hontz, S. R. Yost, P. D. Reusswig, M. E. Bahlke, S. Reineke, T. Van Voorhis and M. A. Baldo, Science, 2013, 340, 334-337.

25 H. Zhen, Q. Hou, K. Li, Z. Ma, S. Fabiano, F. Gao and F. Zhang, J. Mater. Chem. A, 2014, 2, 12390-12396.

26 M. H. Yun, E. Lee, W. Lee, H. Choi, B. R. Lee, M. H. Song, J.-I. Hong, T.-H. Kwon and J. Y. Kim, J. Mater. Chem. C, 2014, 2, 10195-10200.

27 M. Qian, R. Zhang, J. Hao, W. Zhang, Q. Zhang, J. Wang, Y. Tao, S. Chen, J. Fang and W. Huang, Adv. Mater., 2015, 27, 3546-3552.

28 Y.-N. Liu, S.-F. Wang, Y.-T. Tao and W. Huang, Chin. Chem. Lett., 2016, 27, 1250-1258.

29 I. A. Wright, Polyhedron, 2018, 140, 84-98.

30 L. Xu, C.-L. Ho, L. Liu and W.-Y. Wong, Coord. Chem. Rev., 2018, 373, 233-257.

31 Y. Jin, Y. Zhang, Y. Liu, J. Xue, W. Li, J. Qiao and F. Zhang, Adv. Mater., 2019, 31, 1900690.

32 Q. Wu, Y. Cheng, Z. Xue, X. Gao, M. Wang, W. Yuan, S. Huettner, S. Wan, X. Cao, Y. Tao and W. Huang, Chem. Commun., 2019, 55, 2640-2643.

33 J. Benduhn, F. Piersimoni, G. Londi, A. Kirch, J. Widmer, C. Koerner, D. Beljonne, D. Neher, D. Spoltore and K. Vandewal, Adv. Energy Mater., 2018, 8, 1800451.

34 J. Xue, L. Xin, J. Hou, L. Duan, R. Wang, Y. Wei and J. Qiao, Chem. Mater., 2017, 29, 4775-4782.

35 P. N. Murgatroyd, J. Phys. D: Appl. Phys., 1970, 3, 151-156.

36 N. Felekidis, A. Melianas and M. Kemerink, Org. Electron., 2018, 61, 318-328.

37 Z. He, B. Xiao, F. Liu, H. Wu, Y. Yang, S. Xiao, C. Wang, T. P. Russell and Y. Cao, Nat. Photonics, 2015, 9, 174. 